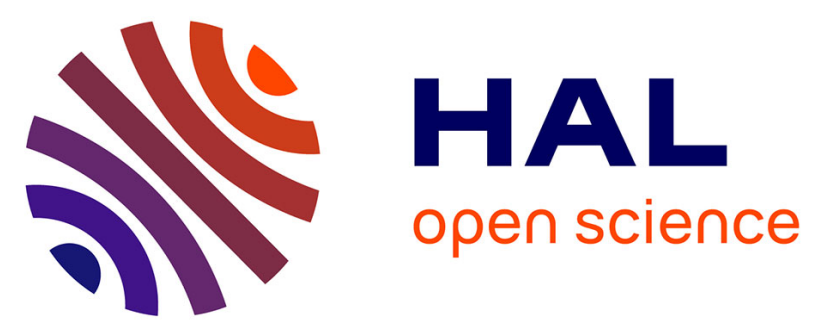

\title{
A role for lipid rafts in the protection afforded by docosahexaenoic acid against ethanol toxicity in primary rat hepatocytes.
}

Fatiha Aliche-Djoudi, Normand Podechard, Aurore Collin, Martine Chevanne, Emilie Provost, Martine Poul, Ludovic Le Hégarat, Daniel D. Catheline, Philippe P. Legrand, Marie-Thérèse Dimanche-Boitrel, et al.

\section{To cite this version:}

Fatiha Aliche-Djoudi, Normand Podechard, Aurore Collin, Martine Chevanne, Emilie Provost, et al.. A role for lipid rafts in the protection afforded by docosahexaenoic acid against ethanol toxicity in primary rat hepatocytes.. Food and Chemical Toxicology, 2013, 60C, pp.286-296. 10.1016/j.fct.2013.07.061 . hal-00860153

\section{HAL Id: hal-00860153}

https://hal-univ-rennes1.archives-ouvertes.fr/hal-00860153

Submitted on 10 Sep 2013

HAL is a multi-disciplinary open access archive for the deposit and dissemination of scientific research documents, whether they are published or not. The documents may come from teaching and research institutions in France or abroad, or from public or private research centers.
L'archive ouverte pluridisciplinaire HAL, est destinée au dépôt et à la diffusion de documents scientifiques de niveau recherche, publiés ou non, émanant des établissements d'enseignement et de recherche français ou étrangers, des laboratoires publics ou privés. 


\section{A role for lipid rafts in the protection afforded by docosahexaenoic acid against ethanol toxicity in primary rat hepatocytes}

Fatiha Aliche-Djoudi ${ }^{1,2}$, Normand Podechard ${ }^{1,2}$, Aurore Collin ${ }^{1,2}$, Martine Chevanne ${ }^{1,2}$, Emilie Provost ${ }^{1,2,3}$, Martine Poul ${ }^{3}$, Ludovic Le Hégarat ${ }^{3}$, Daniel Catheline ${ }^{4}$, Philippe Legrand $^{4}$, Marie-Thérèse Dimanche-Boitrel ${ }^{1,2}$, Dominique Lagadic-Gossmann ${ }^{1,2}$ and Odile Sergent ${ }^{1,2}$

1 : UMR Inserm 1085, IRSET, UFR des Sciences Pharmaceutiques et Biologiques, 2, av Pr Léon Bernard, 35043 Rennes cédex, France

2 : Université de Rennes 1, Biosit UMS3080, 2, av Pr Léon Bernard, 35043 Rennes cédex, France

3 : Anses, Laboratoire de Fougères, Unité de toxicologie des contaminants, BP 90203, 35302 Fougères Cedex, France

4 : USC 2012, Biochimie-INRA, AgrocampusOuest, 65, rue de Saint Brieuc, 35042 Rennes, France

\section{Corresponding author :}

Name : Odile Sergent

Address : UMR Inserm 1085, IRSET, Université de Rennes 1, UFR des Sciences Pharmaceutiques et Biologiques, 2, av Pr Léon Bernard, 35043 Rennes cédex, France

Telephone number : 33(0)223234808

Fax number : 33(0)223234794

E-mail address : osergent@univ-rennes1.fr

\section{Abbreviations :}

DHA, docosahexaenoic acid; EPA, eicosapentaenoic acid; EPR, electron paramagnetic resonance; GM1, monosialotetrahexosyl ganglioside; GPI, glycosylphosphatidylinositol; $\mathrm{H}_{2} \mathrm{FDA}$, dihydrofluorescein diacetate; HNE, 4-hydroxynonenal; LMW iron, low-molecularweight iron; MAL-6, tetramethyl-4-maleimidopiperidine-1-oxyl; O-PFB, pentafluorobenzyloxime; PFBHA·HCl, O-(2,3,4,5,6-pentafluorobenzyl)hydroxylamine hydrochloride; PLC $\gamma 1$, phospholipase $\mathrm{C} \gamma 1$; n-3 PUFA, n-3 polyunsaturated fatty acid; ROS, reactive oxygen species; GSH: reduced glutathione. 


\begin{abstract}
Previously, we demonstrated that eicosapentaenoic acid enhanced ethanol-induced oxidative stress and cell death in primary rat hepatocytes via an increase in membrane fluidity and lipid raft clustering. In this context, another n-3 polyunsaturated fatty acid, docosahexaenoic acid (DHA), was tested with a special emphasis on physical and chemical alteration of lipid rafts. Pretreatment of hepatocytes with DHA reduced significantly ethanol-induced oxidative stress and cell death. DHA protection could be related to an alteration of lipid rafts. Indeed, rafts exhibited a marked increase in membrane fluidity and packing defects leading to the exclusion of a raft protein marker, flotillin. Furthermore, DHA strongly inhibited disulfide bridge formation, even in control cells, thus suggesting a disruption of protein-protein interactions inside lipid rafts. This particular spatial organization of lipid rafts due to DHA subsequently prevented the ethanol-induced lipid raft clustering. Such a prevention was then responsible for the inhibition of phospholipase $\mathrm{C}-\gamma$ translocation into rafts, and consequently of both lysosome accumulation and elevation in cellular low-molecular-weight iron content, a prooxidant factor. In total, the present study suggests that DHA supplementation could represent a new preventive approach for patients with alcoholic liver disease based upon modulation of the membrane structures.
\end{abstract}

Keywords: Lipid rafts; n-3 polyunsaturated fatty acids; docosahexaenoic acid; ethanol; lipid peroxidation; oxidative stress. 


\section{Introduction}

Dietary long chain n-3 polyunsaturated fatty acids (n-3 PUFAs), such as docosahexaenoic acid (DHA) (C22:6, n-3) and eicosapentaenoic acid (EPA) (C20:5, n-3), found naturally in fat fish, have been reported to exhibit beneficial effects in the prevention and treatment of a great variety of human diseases (Calder and Yaqoob, 2009), including inflammatory and autoimmune disorders (Simopoulos, 2002), cancer (Calviello et al., 2009), cardiovascular diseases (Bei et al., 2011), retinopathy (Pawlik et al., 2011) and neurological diseases (Assisi et al., 2006; Dyall and Michael-Titus, 2008). However, we recently demonstrated that EPA was capable of enhancing ethanol-induced oxidative stress and cell death in rat hepatocytes via an exacerbation of membrane remodeling (Aliche-Djoudi et al., 2011). Ethanol metabolism, by producing a mild oxidative stress, increased membrane fluidity (Sergent et al., 2005) and triggered lipid raft clustering, which in turn strikingly enhanced oxidative stress via activation of the phospholipase C signaling pathway (Nourissat et al., 2008). Lipid rafts are highly ordered plasma membrane microdomains, enriched in cholesterol and sphingolipids, that form signaling platforms following clustering (Simons and Toomre, 2000). Interestingly, n-3 PUFAs have been extensively described as modifying the lipid and protein composition of lipid rafts in many cell types such as T lymphocytes (Fan et al., 2004; Stulnig, 2000), Caco-2 cells (Duraisamy et al., 2007), retinal vascular endothelial cells (Chen et al., 2007), macrophages (Wong et al., 2009), and human breast cancer cells (Schley et al., 2007). In this context, the nutritional significance of lipid rafts has been recently pointed out (Yaqoob and Shaikh, 2010). Our results about the toxicity of EPA (Aliche-Djoudi et al., 2011) were in line with those obtained by others in vivo in rats or mice, but none of these latter studies focused on lipid rafts. Thus, in rats chronically fed simultaneously with fish oil and ethanol, an increase in pathology severity (inflammation and necrosis) associated with a rise in lipid peroxidation was observed compared to rats fed with corn oil instead of fish oil (Nanji et al., 1994). In addition, fish oil-ethanol rats exhibited the highest level of apoptotic cells (Yacoub et al., 1995), and of pro-inflammatory cytokine messenger RNAs (Nanji et al., 1999) in the liver. Increased oxidative stress was inversely related to antioxidant enzyme activities and expression in the liver (Polavarapu et al., 1998). Finally, it was also demonstrated that fish oil can synergize with ethanol for the collagen release depending on lipid peroxidation (Nieto, 2007). In contrast, several research teams (Song et al., 2008 ; Wada et al., 2008; Huang et al., 2013) reported that small amounts of DHA or fish oil were able to protect from ethanol-induced fatty liver, oxidative stress, mitochondrial dysfunction and 
necrosis in rodents. However, none of these studies dealing with the beneficial effect of $n-3$ PUFAs on ethanol-induced liver damage looked for the role of lipid rafts, although several studies supported the involvement of these microdomains in the effects of n-3 PUFAs on inflammatory response of lymphocytes (Shaikh and Teague, 2012), endothelial dysfunction (Ye et al., 2010), cancer cell growth (Rogers et al., 2010), and hepatic ischemia/reperfusion injury (Kim et al., 2014). Because of the discrepancies regarding the role of PUFAs towards ethanol-induced liver toxicity, and based upon the increasing body of evidence about the beneficial effects of these compounds on human health, we decided to test another n-3 PUFA, namely DHA, in the context of a lipid-raft dependent toxicity of ethanol in rat hepatocytes. In addition, we evaluated the possible physical and chemical alteration of lipid rafts by DHA. In this paper, DHA was shown to modify lipid rafts, thereby protecting hepatocytes from ethanol-induced oxidative stress and cell death.

\section{Materials and Methods}

\subsection{Chemicals}

Eagle minimum essential medium and medium 199 with Hanks' salts were purchased from Gibco, Invitrogen, (Cergy - Pontoise, France). Bovine serum albumin and fetal calf serum were obtained from Biowest (Nuaille, France). Liberase was from Roche Diagnostics (Meylan, France). Ethanol was obtained from Prolabo (Paris, France). Dehydroethidium (DHE), LysoTracker Red DND-99 (LTR) and cholera toxin subunit B (CTB) were provided by Molecular Probes, Invitrogen, (Cergy-Pontoise, France). Docosahexaenoic acid (DHA), 12-doxyl stearic acid (12-DSA), Hoechst 33342, tetramethyl-4-maleimidopiperidine-1-oxyl (MAL-6) and p-nitrophenyl phosphate solution were all purchased from Sigma-Aldrich (Saint-Quentin Fallavier, France). O-(2,3,4,5,6-Pentafluorobenzyl)hydroxylamine hydrochloride (PFBHA.HCl) was purchased from Fluka (Montigny le Bretonneux, France). HNE-D3 was provided from SPI Bio (Saint-Quentin Fallavier, France). Deferiprone was from Acros (Fischer Scientific, Illkirch, France). Anti- phospholipase C $\gamma 1$, anti-flotillin and anti-malondialdehyde antibodies were purchased from Upstate (Millipore, Saint-Quentin Les Yvelines, France), BD Biosciences (Le Pont de Claix, France) and Abcam (Paris, France), respectively. Anti-mouse and anti-rabbit immunoglobulin G (IgG) was from DAKO (Trappes, France).

\subsection{Cell isolation and cultures}


Adult rat hepatocytes were isolated from 2-months-old Sprague-Dawley animals by perfusion of the liver as previously described, except that a liberase solution $(17 \mu \mathrm{g} / \mathrm{ml})$ was used for dissociation of liver parenchymal cells instead of a collagenase solution (Guguen-Guillouzo et al., 1983). In most cases, cell viability was above $90 \%$. Cells were seeded at densities of 2 x $10^{6}$ in $9.6 \mathrm{~cm}^{2}$ petri dishes (cell death determination, immunofluorescence staining of cells and antioxidant content), $3 \times 10^{4}$ cells/well in 96-well microplates (lysosome quantification), $10 \times 10^{6}$ cells in $78 \mathrm{~cm}^{2}$ petri dishes (membrane fluidity determination), $20 \times 10^{6}$ cells in 176

$\mathrm{cm}^{2}$ petri dishes (low-molecular-weight iron measurement and lipid raft isolation). They were then cultured in a medium composed of $75 \%$ Eagle minimum essential medium and $25 \%$ medium 199 with Hanks' salts, supplemented with $10 \%$ fetal calf serum and containing streptomycin $(50 \mu \mathrm{g})$, penicillin $(5 \mu \mathrm{g})$, insulin $(5 \mu \mathrm{g})$, bovine serum albumin $(1 \mathrm{mg})$, and $\mathrm{NaHCO}_{3}(2.2 \mathrm{mg})$ per milliliter. Cells were kept at $37^{\circ} \mathrm{C}$ in an atmosphere of $5 \% \mathrm{CO}_{2}$ and 95\% air. The medium was changed 3 hours after seeding and substituted with the same medium as above but deprived of serum. Regarding culture treatments, DHA at a final concentration of $200 \mu \mathrm{M}$ was added or not to rat hepatocytes. This concentration was chosen in order to be as close as possible to that detected in plasma after dietary supplementation (around $500 \mu \mathrm{M}$ ) (Wander and $\mathrm{Du}, 2000$ ). In addition, no further protection against ethanolinduced apoptosis was observed at 300 or $500 \mu \mathrm{M}$ DHA concentrations (data not shown). After an 18-hours incubation time at $37^{\circ} \mathrm{C}$, some cultures were supplemented with $50 \mathrm{mM}$ ethanol for $1,1.5$ or 5 hours, while cultures treated with DHA vehicle (methanol $0.12 \%$ ) were used as controls.

\subsection{Lipid Raft Fractionation by Flotation Method}

Lipid rafts are defined as being resistant towards solubilization by nonionic detergents at low temperature. Based on this property, lipid rafts float and concentrate in low-density sucrose gradient upon centrifugation. Thus, adapted from a previously described method (Nourissat et al., 2008), lipid raft fractions were prepared by discontinuous sucrose gradient ultracentrifugation of hepatocyte lysates obtained following treatment with the detergent Triton X 100 at 1\%. Eleven 1-ml fractions were collected from the top of the gradient and then analyzed for protein and lipid content. In some experiments, the whole raft fractions (fractions 1 to 6) were gathered, diluted in PBS and pelleted by another ultracentrifugation at $41000 \mathrm{rpm}$ for $16-20$ hours at $4^{\circ} \mathrm{C}$ in an SW41 rotor. This latter procedure allowed us to pool lipid rafts in a single pellet. 


\subsection{Biochemical analysis of membrane lipid rafts}

2.4.1. Lipid assays. The cholesterol content of each gradient fraction was spectrophotometrically evaluated by a cholesterol oxidase/peroxidase assay using the Infinity Cholesterol kit (Thermo Electron Corp., Eragny sur Oise, France) after lipid extraction by a chloroform/methanol mixture $(2: 1 \mathrm{vol} / \mathrm{vol})$, according to the method of Folch. Total fatty acids were analyzed by gas chromatography equipped with a flame ionization detector after lipid extraction by a hexane/isopropanol mixture (3:2 vol/vol), saponification and methylation of each raft fraction (Aliche-Djoudi et al., 2011).

2.4.2. Protein assays. Flotillin-1 expression was analyzed by western blotting with 1:1000 mouse antiflotillin-1 monoclonal antibody (Nourissat et al., 2008). Alkaline phosphatase activity was determined by a colorimetric method using $p$-nitrophenylphosphate as a substrate (Nourissat et al., 2008).

\subsection{Determination of structural alterations of lipid rafts}

2.5.1. Spin labeling techniques. Using paramagnetic reporter groups incorporated into lipid rafts, Electron Paramagnetic Resonance (EPR) spectroscopy can evaluate both changes in membrane fluidity and protein interactions. Membrane fluidity was measured, as previously described (Nourissat et al., 2008) using the spin label, 12-doxyl stearic acid. The fluidity of the labeled membranes was quantified by calculating the order parameter $\mathrm{S}$, which is inversely related to membrane fluidity. Protein structural changes were examined using tetramethyl-4-maleimidopiperidine-1-oxyl (MAL-6), a thiol-specific protein spin label (Nourissat et al., 2008). The relevant EPR parameter used for the evaluation of protein structural changes is the ratio of the height (W) of the low-field weakly immobilized line to the height $(\mathrm{S})$ of the low-field strongly immobilized line. A decrease in the W/S ratio reveals conformational compactions or increased interactions between membrane proteins (Hensley et al., 1994).

2.5.2. Fluorescent staining of lipid rafts. Lipid rafts were stained by the binding of the cholera toxin subunit B coupled to green fluorescent Alexa Fluor 488 conjugate to the pentasaccharide chain of the lipid raft marker monosialotetrahexosyl ganglioside (GM1), using the Vybrant Lipid Raft Labeling kit (Molecular Probes, Invitrogen, Cergy-Pontoise, France) as previously described (Nourissat et al., 2008). When dual staining was performed, hepatocytes were incubated with both cholera toxin conjugate and the primary monoclonal anti-phospholipase $\mathrm{C} \gamma 1$ antibody $(10 \mu \mathrm{g} / \mathrm{ml})$ for 2 hours, followed by incubation with 1:2000 
TRITC-conjugated anti-mouse immunoglobulin G secondary antibody for an additional 2 hours (Nourissat et al., 2008). Individual and overlay fluorescence were shown following deconvolution analysis using Metavue software.

\subsection{Oxidative stress evaluation}

2.6.1. Determination of reactive oxygen species (ROS) production. Intracellular levels of ROS were measured as previously described (Sergent et al., 2005), except that another probe, dehydroethidium, was used instead of dihydrofluorescein diacetate.

\subsubsection{Evaluation of lipid peroxidation.}

Lipid peroxidation of rat hepatocytes was estimated by using the fluorescent probe, C11BODIPY ${ }^{581 / 591}$, and by measuring free 4-hydroxynonenal. C11-BODIPY ${ }^{581 / 591}$ shifts from red to green fluorescence upon oxidation. Briefly, fluorescence was recorded by a SpectraMax Gemini Spectrofluorimeter (Molecular Devices, France) using two couples of wavelengths to measure the amount of reduced $(\lambda \mathrm{exc}=590 \mathrm{~nm}-\lambda \mathrm{em}=635 \mathrm{~nm})$ and oxidized probe $(\lambda \mathrm{exc}=485 \mathrm{~nm}-\lambda \mathrm{em}=535 \mathrm{~nm})$ (Nourissat et al., 2008). Lipid peroxidation was then quantified by calculating the ratio oxidized probe/total probe.

4-hydroxynonenal (4-HNE) is an $\alpha, \beta$ unsaturated aldehyde, secondary end-product of the oxidized polyunsaturated fatty acid degradation. Briefly, hepatocytes were lysed and centrifuged at $5000 \mathrm{~g}$ for $5 \mathrm{~min}$ at $4{ }^{\circ} \mathrm{C}$. Supernatant $(200 \mu \mathrm{l})$ of each simple was mixed with $50 \mu \mathrm{l}$ of internal standard HNE-D3 $(1 \mu \mathrm{g} / \mathrm{mL})$. The pentafluorobenzyl-oxime derivatives (OPFB) of 4-HNE and of the internal standard were synthesized by adding $200 \mu \mathrm{L}$ of $O$ $(2,3,4,5,6$-pentafluorobenzyl)hydroxylamine hydrochloride (PFBHA $\cdot \mathrm{HCl})(12.5 \mathrm{mg} / \mathrm{ml})$. After incubation of the mixture at room temperature for 1 hour under shaking, $500 \mu 1$ of methanol were added followed by $2 \mathrm{ml}$ hexane addition. Then, sample was mixed with $140 \mu \mathrm{l}$ of concentrated sulfuric acid to eliminate excess of PFBHA.HCl, before mixing and centrifugation of the sample at $3000 \mathrm{~g}$ for $5 \mathrm{~min}$ at $4{ }^{\circ} \mathrm{C}$. After separation, hexane fractions were collected, dried over anhydrous sodium sulfate and evaporated under nitrogen at $50{ }^{\circ} \mathrm{C}$ for $5 \mathrm{~min}$; this was followed by silylation of hydroxyl group to trimethylsilyl ethers (TMS) by adding of $50 \mu \mathrm{l}$ of $\mathrm{N}, \mathrm{O}$-bis(trimethylsilyl)trifluoroacetamide and trimethylchlorosilane (BSTFA + TMCS) (99:1) (Supelco, Saint-Quentin Fallavier, France), for $15 \mathrm{~min}$ at $80{ }^{\circ} \mathrm{C}$. Then, $50 \mu 1$ of hexane was added to the sample, and the O-PFB-TMS derivative of 4-HNE was analyzed by gas chromatography-mass spectrometry (GC/MS) equipped with a capillary column [capillary column HP-5MS : (5 \% phenyl)-methylpolysiloxane] (Agilent 19091S- 
433, Agilent Technologies France, Massy) (30 m, $0.25 \mathrm{~mm}$ internal diameter, $0.25 \mu \mathrm{m}$ film thickness), and a mass spectrometry detector in the single ion monitoring (SIM) mode (Mass selective detector Hewlett Packard 5973, Agilent Technologies France, Massy). The column temperature program started at $60^{\circ} \mathrm{C}$ for $1 \mathrm{~min}$, ramped at $20^{\circ} \mathrm{C} / \mathrm{min}$ to $85^{\circ} \mathrm{C}$, and then the temperature was increased to $300^{\circ} \mathrm{C}$ at $8^{\circ} \mathrm{C} / \mathrm{min}$.

2.6.3. Measurement of low molecular weight iron. Intracellular low-molecular-weight-iron (LMW iron) was measured by EPR based upon the capacity of deferiprone to chelate only low-molecular-weight iron and to give a paramagnetic chelate, as previously described (Sergent et al., 1997).

\subsubsection{Estimation of intracellular antioxidants}

Reduced glutathione (GSH) levels, manganese superoxide dismutase (Mn SOD), Cu, Zn superoxide dismutase $(\mathrm{Cu}, \mathrm{Zn}$ SOD) and glutathione peroxidase (GPx) activities were estimated using the Bioxytech GSH/GSSG-412 colorimetric assay kit (Oxis International, Tebu-Bio, Le Perray en Yveline, France), a superoxide dismutase activity kit (Assaydesigns, Stressgen, Paris, France), and the Biotech GPx -340 colorimetric assay kit (Oxis International, Tebu-Bio, Le Perray en Yveline, France), respectively.

\subsection{Evaluation of cell death by nuclear staining}

Chromatin condensation and morphological changes in the nucleus were observed using the chromatin dye Hoechst 33342. After a 5-hours incubation with ethanol, cells were stained in culture medium with $10 \mu \mathrm{g} / \mathrm{ml}$ Hoechst 33342 in the dark for 30 minutes at $37^{\circ} \mathrm{C}$. Cells were then examined under fluorescence microscopy (Olympus BX60, France). Total population was always $>200$ cells.

\subsection{Lysosome staining}

Lysosomes were labeled with LysoTracker Red, a red acidotropic fluoroprobe. At the end of each treatment, rat hepatocytes, cultured on glass coverslips, were incubated with $200 \mathrm{nM}$ LysoTracker Red for 5 minutes at $37^{\circ} \mathrm{C}$. Cells were then fixed with $4 \%$ paraformaldehyde in PBS for 30 minutes at $4{ }^{\circ} \mathrm{C}$. The red fluorescence of LysoTracker was visualized by fluorescence microscopy (DMRXA Leica, Germany).

\subsection{Statistical analysis}

Data are presented as mean \pm SD and were analyzed using one-way ANOVA followed by a 
Student-Newman-Keuls multiple comparison test. A value of $\mathrm{p}<0.05$ was considered statistically significant.

\section{Results}

\subsection{Protective effect of DHA towards ethanol-induced cell death and oxidative stress in rat hepatocytes}

As previously shown (Nourissat et al., 2008), ethanol exposure of rat hepatocytes increased both cell death (Figure 1A) and oxidative stress as assessed by measuring ROS production (Figure 1B) and lipid peroxidation (Figures 1C-1D). DHA pretreatment inhibited all these effects. Treatment with DHA alone did not lead to any change in cell death and oxidative stress compared to control conditions. In order to further explore the DHA protective effect on oxidative stress, we decided to evaluate the levels of various antioxidants in hepatocytes. After pretreatment with DHA, no change in activities of $\mathrm{Mn}$ superoxide dismutase, $\mathrm{Cu} / \mathrm{Zn}$ superoxide dismutase and glutathione peroxidase was detected except for glutathione concentration (Figure 2). Indeed, this concentration increased by nearly $16 \%$ when compared to control cultures. No further elevation was detected when compared to ethanol alone.

\subsection{DHA-induced biochemical alterations of lipid rafts}

As we previously showed that ethanol toxicity in hepatocytes was closely related to biochemical and physical alterations of lipid rafts (Nourissat et al., 2008), we were then interested in looking for possible DHA effect on lipid rafts.

\subsubsection{Lipid composition of lipid rafts}

Gas chromatography analysis of fatty acid profiles showed that, as previously described (Aliche-Djoudi et al., 2011), lipid rafts from control rat hepatocytes were significantly enriched in saturated and monounsaturated fatty acids, while polyunsaturated fatty acids were less abundant (Figure 3A), testifying the high lipid-ordered state of these specialized membrane microdomains. Treatment of rat hepatocytes with DHA led to a significant increase in polyunsaturated fatty acids and a decrease in saturated fatty acids, while no significant change in monounsaturated fatty acids was observed (Figure 3A). Ethanol addition did not modify fatty acid profiles when compared to control hepatocytes or DHA pretreated cells (data not shown). When considering the DHA specific levels (Figure 3B), it was shown that DHA was incorporated into rafts in a greater proportion $(+42 \%)$ compared to non-raft regions ( $+23 \%$ ), even if DHA is well-known to have a high steric incompatibility 
with cholesterol, a major lipid raft component. Unexpectedly, DHA did not lead to any change in the cholesterol composition of lipid rafts (Figure 3C), like upon ethanol addition (control : $0.685 \pm 0.032 \mu \mathrm{mol}$ cholesterol/mg protein ; ethanol : $0.684 \pm 0.031 \mu \mathrm{mol} / \mathrm{mg}$ protein ; DHA : $0.765 \pm 0.15$; ethanol + DHA : $0.751 \pm 0.14 \mu \mathrm{mol} / \mathrm{mg}$ protein). Thus, it appears that, in hepatocytes, for this $50 \mathrm{mM}$ concentration, ethanol did not lead to any lipid raft disruption, suggesting an apparent contradiction when considering literature. Indeed, an ethanol-induced disruption was previously established, but it was only for higher concentrations $(200 \mathrm{mM})$ and only in macrophages (Fernandez-Lizarbe et al, 2007). For lower ethanol concentrations, in macrophages (Dai et al, 2005), monocytes (Dolganiuc et al, 2006) or T lymphocytes (Ghare et al, 2011), no change in lipid raft protein markers was reported.

\subsubsection{Protein expression analysis of both soluble and detergent-resistant fractions}

Immunoblotting of both raft and non raft fractions with antibody against flotillin-1, a lipid raft protein marker, revealed that DHA induced a slight shift of flotillin-1 toward the non raft fractions (Figure 3D), suggesting an exclusion of flotillin from rafts or a lower resistance of lipid rafts to detergent solubilisation.

\section{DHA effect on the physical alteration of lipid raft induced by ethanol}

\subsection{Membrane fluidity}

DHA increased membrane fluidity of lipid rafts compared to that of rafts obtained from control cells, but did not enhance ethanol-induced fluidization of lipid rafts (Figure 4A). Similarly, DHA did not modify ethanol-induced membrane fluidization of bulk membranes (Figure 4A).

\subsection{Lipid raft aggregation}

Lipid raft aggregation was determined by the staining of a lipid raft marker, ganglioside GM1, with green fluorescent-labeled cholera toxin B subunit. As previously shown (Nourissat et al., 2008), ethanol treatment induced lipid raft aggregation characterized by the accumulation of fluorescent-labeled cholera toxin B subunit 1 as a punctuated pattern in the plasma membrane, indicative of a redistribution of ganglioside GM1 into clusters (Figure 4B). In control hepatocytes, GM1 distributed throughout the membrane as indicated by the diffuse green fluorescence. DHA pretreatment inhibited ethanol-induced lipid aggregation, as exhibited by the diffuse green fluorescence pattern. To further understand how DHA 
protected from ethanol-induced lipid raft clustering, we used MAL-6, a thiol-specific protein spin label, which can binds covalently to free sulfhydryl $(\mathrm{SH})$ groups. A decrease in the W/S ratio reveals conformational compactions or increased interactions between membrane proteins (Hensley et al., 1994). A decrease in the W/S ratio was obtained in lipid rafts from ethanol-treated hepatocytes, which was previously ascribed to the raft protein oxidation and the formation of disulfide bridges between lipid rafts, thus promoting lipid raft aggregation (Nourissat et al., 2008). Pretreatment of rat hepatocytes with DHA considerably increased W/S ratio, even upon ethanol exposure, suggesting a reduction of disulfide bridges or a decrease in lipid raft compaction (Figure 4C).

\section{DHA inhibition of phospholipase $\mathrm{C} \gamma 1$ (PLC $\gamma 1)$ relocation to lipid rafts was involved in} the DHA protection against ethanol-induced oxidative stress and cell death.

Following raft clustering, relocation of PI-PLC $\gamma 1$ to lipid rafts was shown as allowing its own activation; this was necessary to enhance ethanol-induced oxidative stress and cell death via a lysosome accumulation and an increase in low molecular weight (LMW) iron content (Nourissat et al., 2008) (Aliche-Djoudi et al., 2011). These iron species are known to trigger oxidative stress by catalyzing the formation of a highly hydroxyl radical, via a Fenton or Haber-Weiss reaction, or more directly by the production of ferryl and perferryl species. These iron species are not contained in high-molecular-weight molecules such as ferritin or mitochondrial ferroproteins.

As previously described for ethanol-treated hepatocytes, merging of fluorescence stainings led to the appearance of yellow patches, which indicated clustering or colocalization of PLC $\gamma 1$ with GM1. When cells were pretreated with DHA prior to ethanol, the colocalization of PLC $\gamma 1$ with GM1 was completely blocked (Figure 5A). In addition, DHA pretreatment also inhibited PLC $\gamma 1$ activity. Indeed, alkaline phosphatase activity was significantly increased when cells were pretreated by DHA (Figure 5B). Alkaline phosphatase is a glycosylphosphatidylinositol (GPI)-anchored protein tethered to the outer leaflet of lipid raft that is known to be a target for PLC $\gamma 1$. Thus, these results suggested that DHA inhibited both PLC $\gamma 1$ relocation to rafts and its subsequent activation. As expected, DHA also prevented both the lysosome accumulation (Figure 6A) and the increase in cellular LMW iron content due to ethanol (Figure 6B). 


\section{Discussion}

In this study, docosahexaenoic acid (DHA), a n-3 PUFA, was demonstrated to protect from the ethanol induced-cell death of primary rat hepatocytes through inhibition of oxidative stress; this is in contrast to our previous results reporting the increase of ethanol toxicity upon exposure to another n-3 PUFA, namely eicosapentaenoic acid (EPA) (Aliche-Djoudi et al., 2011). Our findings could explain the discrepancies observed in literature about the effects of fish oil or n-3 PUFAs on ethanol-induced liver toxicity. Indeed, when examining the studies describing a protection by n-3 PUFAs towards the oxidative/nitrosative stress or steatosis due to ethanol, it is noteworthy that it concerns an administration to rodents of DHA alone or fish oil containing a high proportion of DHA (Song et al., 2008; Wada et al., 2008; Huang et al, 2013). In addition, Hayashi et al. (1999) also reported a protection when human received phospholipids containing a higher proportion of DHA than EPA. Finally, treatment of rats with DHA also protected from induced nonalcoholic steatohepatitis by decreasing oxidative stress (Takayama et al., 2010). At the opposite, the studies demonstrating an exacerbation of fatty liver, inflammation or fibrosis in rodents (Nanji et al., 1994, 1999; Nieto et al., 2007; Polavarapu et al., 1998; Yacoub et al., 1995) used fish oil with a higher proportion of EPA. These differences on ethanol liver toxicity as a function of the n-3 PUFA compound suggested that the relative amounts of EPA and DHA in diets or fish oil supplements may differentially modulate the progression of alcoholic liver disease. Such a differential effect for two compounds of a same fatty acid family might be surprising, but others also reported differential effects of EPA and DHA on cell functions (Gorjao et al., 2009) such as ion homeostasis, intracellular signaling or gene expression.

In primary rat hepatocytes, the DHA beneficial effects as compared to the EPA toxic effects towards ethanol-induced liver toxicity could be related to differences in their physical properties within membranes. Indeed, DHA exposure of hepatocytes led to its incorporation both in lipid rafts and non-raft regions. Such a DHA incorporation into lipid rafts was also reported in vitro after DHA treatment of Jurkat T lymphocytes (Li et al., 2005), EL4 B lymphocytes (Shaikh et al., 2009), human retinal endothelial cells (Chen et al., 2007), Caco-2 cells (Duraisamy et al., 2007), and in vivo in B lymphocytes of mice treated with fish oil (Rockett et al., 2012). In addition, based upon the DHA aversion for cholesterol (Wassal and Stillwell, 2009), one might have expected that DHA incorporation into lipid rafts would drive the cholesterol expulsion from them. However, in our cellular model, cholesterol levels did not change in lipid rafts in line with observations obtained in vitro (Shaikh et al., 2009) and in vivo (Rockett et al., 2012) in B lymphocytes. Using quantitative microscopy studies, these 
authors also showed that DHA or fish oil increased lipid raft size, thus suggesting that DHAcontaining phospholipids would form their own distinct non raft regions on a nanometer scale within lipid rafts (Shaikh et al., 2009). In our model, by means of three approaches, the study of lipid raft structure supported this concept of lipid raft disorganization. First, flotillin was partially evicted from raft isolated by non-ionic detergent procedure suggesting a partial lipid raft disruption. Thus, it has been described that disturbance of polar or hydrophobic interactions inside lipid rafts induced transient packing defects that favor detergent solubilisation (Patra et al., 1998). In addition, DHA strongly decreased lipid raft compaction and perhaps the formation of disulfide bridges, even in control cells, thus suggesting a disruption of protein-protein interactions inside lipid rafts. Finally, lipid rafts exhibited a profound increase in membrane fluidity. This particular spatial organization of lipid rafts might be responsible for the DHA inhibition of ethanol-induced lipid raft aggregation. At the opposite, EPA toxic effect was found to be linked to its preferential incorporation in non-raft regions, which favored translocation of cholesterol to lipid rafts, thus enhancing lipid phase segregation between raft and non-raft domains and hence lipid raft clustering (Aliche-Djoudi et al., 2011). It should be added that, in a similar way, in model membranes, DHA was shown to incorporate more easily in lipid rafts than EPA (Williams et al, 2012). Furthermore in B lymphocytes, Shaikh et al. (2009) obtained inhibition of clustering with DHA but not with EPA. The DHA effect on lipid raft clustering had important consequences in terms of cytoprotection. Indeed, ethanol-induced oxidative stress was previously demonstrated to be related to this clustering which allowed the activation of PLC $\gamma 1$ and then the elevation of LMW iron, a potent pro-oxidant factor, via an increase in lysosome number. Here, DHA was found to inhibit this process. In this context, one might assume for the first time, that DHAinduced structural changes of lipid rafts could be the mechanism whereby this fatty acid protects liver from ethanol induced-toxicity.

However, we cannot totally rule out the possibility that the DHA antioxidant effect would involve an increase in antioxidant levels, notably glutathione (Komatsu et al., 2003) and glutathione peroxidase (Joulain et al., 1994; Lemaitre et al., 1997), as previously described in various cell types including macrophages, platelets or monocytes. Indeed, DHA has been reported to trigger oxidative stress in endothelial cells, which in turn can induce the expression of glutathione peroxidase as an adaptive response (Delton-Vandenbroucke et al., 2001). In addition, more recently, peroxidation products derived from DHA have been described to activate $\mathrm{Nrf} 2$, a transcription factor controlling antioxidant gene expression (Gao 
et al., 2007). In this context, we decided to study several antioxidant levels or enzyme activities. No changes in $\mathrm{Cu} / \mathrm{Zn}$ superoxide dismutase, $\mathrm{Mn}$ superoxide dismutase, or glutathione peroxidase activities were detected after treatment of hepatocytes with DHA. Only a slight increase in glutathione levels was obtained upon DHA exposure compared to control cells and without any further elevation compared to ethanol. In addition, DHA did not induce any elevation of lipid peroxidation in total membranes. It was also previously reported in blood platelets, that DHA could exert anti-oxidant effects at low doses $(0.5 \mu \mathrm{M})$ whereas a lipid peroxidation was induced at higher concentrations $(50 \mu \mathrm{M})$ (Lagarde et al., 2012; Véricel et al., 2003). Unlike these results, we have found that in rat hepatocytes, DHA cytoprotection increased with concentration (50 to $300 \mu \mathrm{M}$ ) (data not shown). Taken altogether, these data strongly suggested the absence of a direct antioxidant effect of DHA in rat hepatocytes, but highlighted the main role of lipid rafts. In addition, it should be noted that, in endothelial cells, DHA was also demonstrated to suppress ROS-induced calcium influx via lipid raft alterations (Ye et al., 2010). However, one cannot yet exclude an antioxidant effect of DHA metabolites. Indeed, Gonzalez- Périz et al. (2006) reported that derived lipid mediators generated from DHA metabolism, namely protectin D1 and $17 S$ hydroxy-DHA, protected from carbon tetrachloride- or $\mathrm{H}_{2} \mathrm{O}_{2}$-induced lipid peroxidation in murine liver or hepatocytes, respectively. From our data, it appears that the main DHA target, responsible for its antioxidant effect, may be plasma membrane. Consequently, DHA might be proposed for the prevention/treatment of alcoholic liver diseases, either alone or associated with other "anti-oxidant" therapies such as vitamin $\mathrm{E}$, silymarin, quercetin, $\mathrm{N}$-acetylcysteine or S-adenosylmethionine, that display other mechanisms of action. As accumulating experimental evidences both in vitro and in vivo supported the critical role of oxidative stress in ethanol-induced liver injury (Albano, 2008; Cohen et al., 2011; Feldstein and Bailey, 2011; $\mathrm{Wu}$ and Cederbaum, 2009; Zhu et al., 2012), it is essential to propose the development of new antioxidant strategies. Indeed, no convincing results have been obtained yet from clinical trials with the different antioxidants quoted above (Bergheim et al, 2004; Bjelakovic et al., 2012; Singal et al., 2011; Tome and Lucey, 2004; Zhu et al., 2012). In this context, bench to bedside research to test the DHA efficacy in alcoholic liver disease, used either alone or combined with other antioxidant compounds, should be encouraged.

In summary, our data indicated that DHA significantly reduced ethanol-induced oxidative stress and cell death in rat hepatocytes. This effect was demonstrated, for the first time, to be likely associated with lipid raft alteration leading to the inhibition of ethanol-induced raft clustering and PLC $\gamma 1$ translocation into lipid rafts (Figure 7). Consequently, DHA inhibited 
PLC $\gamma 1$ activation and hence the lysosome accumulation responsible for the elevation of cellular content of LMW iron, a potent pro-oxidant factor. Finally, intake of n-3 PUFA, provided that it is DHA, might represent a good preventive approach for patients with alcoholic liver disease based upon raft targeting, as it was previously described for cancer (Mollinedo and Gajate, 2010; Mollinedo et al., 2010).

Acknowledgements : We thank the microscopy platform MRic (SFR Biosit, Rennes, France) and Stephanie Dutertre for helpful advice on fluorescence microscopy. We also thank animal house platform (SFR Biosit, Rennes, France) and Laurence Bernard-Touami for her assistance. We are also very grateful to Chu Ya for his technical assistance and Pr. Vincent Rioux for his valuable discussions. European union (FEDER), the Region Bretagne, the Conseil Général d'Ille-et-Vilaine, Rennes Métropole and the French Ministère de l'Enseignement Supérieur et de la Recherche (MESR) are also thanked for the financial support of the project Membratox (Contract number 32508, 350 keuros). This work was supported by the Institut de Recherches Scientifiques sur les Boissons (IREB) (contract numbers 2007/26, 2008/25, 2009/28, 2010/18) and the Région Bretagne (which provided a grant to Fatiha Aliche-Djoudi).

\section{References}

Albano, E., 2008. Oxidative mechanisms in the pathogenesis of alcoholic liver disease. Molec. Asp. Med., 29, 9-16.

Aliche-Djoudi, F., Podechard, N., Chevanne, M., Nourissat, P., Catheline, D., Legrand, P., Dimanche-Boitrel, M.-T., Lagadic-Gossmann, D., Sergent, O., 2011. Physical and chemical modulation of lipid rafts by a dietary n-3 polyunsaturated fatty acid increases ethanol-induced oxidative stress. Free Radic. Biol. Med. 51, 2018- 2030.

Assisi, A., Banzi, R., Buonocore, C., Capasso, F., Di Muzio, V., Michelacci, F., Renzo, D., Tafuri, G., Trotta, F., Vitocolonna, M., Garattini, S., 2006. Fish oil and mental health : the role of n-3 long-chain polyunsaturated fatty acids in cognitive development and neurological disorders. Int. Clin. Psychopharmacol. 21, 319-336.

Bei, R., Frigiola, A., Masuelli, L., Marzocchella, L., Tresoldi, I., Modesti, A., Galvano, F., 2011. Effects of omega-3 polyunsaturated fatty acids on cardiac myocyte protection. Front. Biosci. 16, 1833-1843.

Bergheim, I., McClain, C.J., Arteel, G.E. 2005. Treatment of alcoholic liver disease. Dig. 
Dis. 23, 275-284.

Bjelakovic, G., Gluud, L.L., Nikolova, D., Bjelakovic, M., Nagorni, A., Gluud, C. 2010. Meta-analysis : antioxidant supplements for liver diseases - the Cochrane hepatobiliary group. Aliment. Pharmacol. Ther. 32, 356-367.

Calder, P.C., Yaqoob, P., 2009. Omega-3 polyunsaturated fatty acids and human health outcomes. Biofactors. 35, 266-272.

Calviello, G., Serini, S., Piccioni, E., Pessina, G., 2009. Antineoplastic effects of n-3 polyunsaturated fatty acids in combination with drugs and radiotherapy : preventive and therapeutic strategies. Nutr. Cancer. 61, 287-301.

Chen, W., Jump, D.B., Esselman, W.J., Busik, J.V., 2007. Inhibition of cytokine signaling in human retinal endothelial cells through modification of caveolae/lipid rafts by docosahexaenoic acid. Invest. Ophtalmol. Vis. Sci. 48, 18-26.

Cohen, J.I., Chen, X., Nagy, L.E., 2011. Redox signaling and the innate immune system in alcoholic liver disease. Antioxid. Redox Signal. 15, 523-534.

Dai, Q., Zhang, J., Pruett, S.B., 2005. Ethanol alters cellular activation and CD14 partitioning in lipid rafts. Biochem. Biophys. Res. Comm. 332, 37-42.

Delton-Vandenbroucke, I., Véricel, E., Januel, C., Carreras, M., Lecomte, M., Lagarde, M., 2001. Dual regulation of glutathione peroxidase by docosahexaenoic acid in endothelial cells depending on concentration and vascular bed origin. Free Radic. Biol. Med. 30, 895-904.

Dolganiuc, A., Bakis, G., Kodys, K., Mandrekar, P., Szabo, G., 2006.Acute ethanol treatment modulates toll-like receptor-4 association with lipid rafts. Alcohol. Clin. Exp. Res. 30, 76-85. Duraisamy, Y., Lambert, D., O'Neill, C.A., Padfield, P.J., 2007. Differential incorporation of docosahexaenoic acid into distinct cholesterol-rich membrane raft domains. Biochem. Biophys. Res. Commun. 360, 885-890.

Dyall, S.C., Michael-Titus, A.T., 2008. Neurological benefits of omega-3 fatty acids. Neuromolecular. Med. 10, 219-235.

Fan, Y.-Y., Ly, L.H., Barhoumi, R., McMurray, D.N., Chapkin, R.S., 2004. Dietary docosahexaenoic acid suppresses $\mathrm{T}$ cell protein kinase $\mathrm{C}$ theta lipid raft recruitment and IL-2 production. J. Immunol. 173, 6151-6160.

Feldstein, A.E., Bailey, S.M., 2011. Emerging role of redox dysregulation in alcoholic and nonalcoholic fatty liver disease. Antioxid. Redox Signal., 15, 421-424.

Fernandez-Lizarbe, S., Pascual, M., Gascon, M.S., Blanco, A., Guerri, C. 2008. Lipid rafts regulate ethanol-induced activation of TLR4 signaling in murine macrophages. Molec. Immunol. 45, 2007-2016. 
Gao, L., Wang, J., Sekhar, K.R., Yin, H., Yared, N.F., Schneider, S.N., Sasi, S., Dalton, T.P., Anderson, M.E., Chan, J.Y., Morrow, J.D., Freeman, M.L., 2007. Novel n-3 fatty acid oxidation products activate Nrf2 by destabilizing the association between Keap1 and Cullin3. J. Biol. Chem. 282, 2529-2537.

Ghare, S., Patil, M., Hote, P., Suttles, J., McClain, C., Barve, S., Joshi-Barve, S., 2011. Ethanol inhibits lipid raft-mediated TCR signaling and IL-2 expression potential mechanism of alcohol-induced immune suppression. Alcohol. Clin. Exp. Res. 35, 1-10.

González-Périz, A., Planagumà, A., Gronert, K., Miquel, R., López-Parra, M., Titos, E., Horrillo, R., Ferré, N., Deulofeu, R., Arroyo, V., Rodés, J., Claria, J., 2006. Docosahexaenoic acid (DHA) blunts liver injury by conversion to protective lipid mediators: protectin D1 and 17S-hydroxy-DHA. FASEB J. 20, 2537-2539.

Gorjão, R., Azevedo-Martins, A.K., Rodrigues, H.G., Abdulkader, F., Arcisio-Miranda, M., Procopio, J., Curi, R., 2009. Comparative effects of DHA and EPA on cell function. Pharmacol. Ther. 122, 56-64.

Guguen-Guillouzo, C., Clement, B., Beaumont, C., Morel-Chany, E., Glaise, D., Guillouzo, A., 1983. Maintenance and reversibility of active albumin secretion by adult rat hepatocytes co-cultured with another liver epithelial cell type. Exp. Cell. Res. 143, 47-54.

Hayashi, H., Tanaka, Y., Hibino, H., Umeda, Y., Kawamitsu, H, Fujimoto, H., Amakawa, T., 1999. Beneficial effect of salmon roe phosphatidylcholine in chronic liver disease. Curr. Med. Res. Opin. 15, 177-184.

Hensley, K., Carney, J., Hall, N., Shaw, W., Butterfield, D.A., 1994. Electron paramagnetic resonance investigations of free radical-induced alterations in neocortical synaptosomal membrane protein infrastructure. Free Radic. Biol. Med. 17, 321-331.

Huang, L.L, Wan, J.B., Wang, B., He, C.W., Ma, H., Li, T.W., Kang J.X., 2013. Suppression of acute ethanol-induced hepatic steatosis by docosahexaenoic acid is associated with downregulation of stearoyl-Co1 desaturase 1 and inflammatory cytokines. Prostaglandins, Leukot. Essent. Fatty acids. 88, 347-353.

Joulain, C., Prigent, A.F., Némoz, G., Lagarde, M., 1994. Increased glutathione peroxidase activity in human blood mononuclear cells upon in vitro incubation with n-3 fatty acids. Biochem. Pharmacol. 47, 1315-1323.

Kim K., Jung N., Lee K., Choi J., Kim S., Jun J., Kim E., Kim D., 2013. Dietary omega-3 polyunsaturated fatty acids attenuate hepatic ischemia/reperfusion injury in rats by modulating toll-like receptor recruitment into lipid rafts. Clin. Nutr., in press. 
Komatsu, W., Ishihara, K., Murata, M., Saito, H., Shinohara, K., 2003. Docosahexaenoic acid suppresses nitric oxide production and inducible nitric oxide synthase expression in interferon-gamma plus lipopolysaccharide-stimulated murine macrophages by inhibiting the oxidative stress. Free Radic. Biol. Med. 34, 1006-1016.

Lagarde, M., Calzada, C., Guichardant, M., Véricel, E., 2013. Dose-effect and metabolism of docosahexaenoic acid : pathophysiological relevance in blood platelets. Prostaglandins, Leukot. Essent. Fatty Acids. 88, 49-52.

Lemaitre, D., Véricel, E., Polette, A., Lagarde, M., 1997. Effects of fatty acids on human platelet glutathione peroxidase: possible role of oxidative stress. Biochem. Pharmacol. 53, 479-486.

Li, Q., Wang, M., Tan, L., Wang, C., Ma, J., Li, N., Li, Y., Xu, G., Li, J. 2005. Docosahexaenoic acid changes lipid composition and interleukin-2 receptor signaling in membrane rafts. J. Lipid Res. 46, 1904-1913.

Mollinedo, F., Gajate, C., 2010. Lipid rafts and clusters of apoptotic signaling moleculeenriched rafts in cancer therapy. Future Oncol. 26, 811-821.

Mollinedo, F., de la Iglesia-Vicente, J., Gajate, C., Estella-Hermoso de Mendoza, A., VillaPulgarin, J.A., Campanero, M.A., Blanco-Prieto, M.J. 2010. Lipid raft-targeted therapy in multiple myeloma. Oncogene, 29, 3748-3757.

Nanji, A.A., Zhao, S., Sadrzadeh, S.M., Dannenberg, A.J., Tahan, S.R., Waxman, D.J., 1994. Markedly enhanced cytochrome P450 2E1 induction and lipid peroxidation is associated with severe liver injury in fish oil-ethanol-fed rats. Alcohol. Clin. Exp. Res. 18, 1280-1285.

Nanji, A.A., Jokelainen, K., Rahemtulla, A., Miao, L., Fogt, F., Matsumoto, H., Tahan, S.R., Su, G.L., 1999. Activation of nuclear factor kappa B and cytokine imbalance in experimental alcoholic liver disease in the rat. Hepatology. 30, 934-943.

Nieto, N., 2007. Ethanol and fish oil induce NFkappaB transactivation of the collagen alpha2(I) promoter through lipid peroxidation-driven activation of the PKC-PI3K-Akt pathway. Hepatology. 45, 1433-1445.

Nourissat, P., Travert, M., Chevanne, M., Tekpli, X., Rebillard, A., Le Moigne-Muller, G., Rissel, M., Cillard, J., Dimanche-Boitrel, M.-T., Lagadic-Gossmann, D., Sergent, O., 2008. Ethanol induces oxidative stress in primary rat hepatocytes through the early involvement of lipid raft clustering. Hepatology. 47, 59-70.

Patra, S.K., Alonso, A., Goni, F.M., 1998. Detergent solubilisation of phospholipid bilayers in the gel state : the role of polar and hydrophobic forces. Biochim. Biophys. Acta 1373, 112118. 
Pawlik, D., Lauterbach, R., Turyk, E., 2011. Fish-oil fat emulsion supplementation may reduce the risk of severe retinopathy in VLBW infants. Pediatrics. 127, 223-228.

Polavarapu, R., Spitz, D.R., Sim, J.E., Follansbee, M.H., Oberley, L.W., Rahemtulla, A., Nanji, A.A., 1998. Increased lipid peroxidation and impaired antioxidant enzyme function is associated with pathological liver injury in experimental alcoholic liver disease in rats fed diets high in corn oil and fish oil. Hepatology. 27, 1317-1323.

Rockett, B.D., Teague, H., Harris, M., Melton, M., Williams, J., Wassall, S.R., Shaikh, S.R., 2012. Fish oil increases raft size and membrane order of B cells accompanied by differential effects on function. J. Lipid Res. 53, 674-685.

Rogers K.R., Kikawa K.D., Mouradian M., Hernandez K., McKinnon K.M., Ahwah S.M., Pardini R.S., 2010. Docosahexaenoic acid alters epidermal growth factor receptor-related signaling by disrupting its lipid rafts association. Carcinogenesis. 31, 1523-1530.

Schley, P.D., Brindley, D.N., Field, C.J., 2007. (n-3) PUFA alter raft lipid composition and decrease epidermal growth factor receptor levels in lipid rafts of human breast cancer cells. J. Nutr. 137, 548-553.

Sergent, O., Pereira, M., Belhomme, C., Chevanne, M., Huc, L., Lagadic-Gossmann, D., 2005. Role for membrane fluidity in ethanol-induced oxidative stress of primary rat hepatocytes. J. Pharmacol. Exp. Ther. 313, 104-111.

Shaikh, S.R. and Teague H., 2012. N-3 fatty acids and membrane microdomains : from model membranes to lymphocyte function. Prostaglandins Leukot. Essent. Fatty Acids. 87, 205-208.

Shaikh, S.R., Rockett, B.D., Salameh, M., Carraway, K., 2009. Docosahexaenoic acid modifies the clustering and size of lipid rafts and the lateral organization and surface expression of MHC class I of EL4 cells. J. Nutr. 139, 1632-1639.

Simons, K., Toomre, D., 2000. Lipid rafts and signal transduction. Nat. Rev. Mol. Cell. Biol. 1, 31-39.

Simopoulos, A.P., 2002. Omega-3 fatty acids in inflammation and autoimmune diseases. J Am. Coll. Nutr. 21, 495-505.

Singal, A.K., Jampana, S.C., Weinman, S.A., 2011. Antioxidants as therapeutic agents for liver disease. Liver Int. 31, 1432-1448.

Song, B.J., Moon, K.H., Olsson, N.U., Salem, N.J., 2008. Prevention of alcoholic fatty liver and mitochondrial dysfunction in the rat by long-chain polyunsaturated fatty acids. J. Hepatol. 49, 262-273.

Stulnig, T.M., Huber, J., Leitinger, N., Imre, E.-M., Angelisova, P., Nowotny, P., Waldhausl, 
W., 2001. Polyunsaturated eicosapentaenoic acid displaces proteins from membrane rafts by altering raft lipid composition. J. Biol. Chem. 276, 37335-37340.

Takayama, F., Nakamoto, K., Totani, N., Yamanushi, T., Kabuto, H., Kaneyuki, T., Mankura, M., 2010. Effects of docosaheaxaenoic acid in an experimental rat model of nonalcoholic steatohepatitis. J. Oleo. Sci. 59, 407-414.

Tome, S., Lucey, M.R. 2004. Review article : current management of alcoholic liver disease. Aliment. Pharmacol. Ther. 19, 707-714.

Véricel, E., Polette, A., Bacot, S., Calzada, C., Lagarde, M., 2003. Pro- and antioxidant activities of docosahexaenoic acid on human blood platelets. J. Thromb. Haemost. 1, 566572 .

Wada, S., Yamazaki, T., Kawano, Y., Miura, S., Ezaki, O., 2008. Fish oil fed prior to ethanol administration prevents acute ethanol-induced fatty liver in mice. J. Hepatol. 49, 441-450.

Wander, R.C., Du, S.H., 2000. Oxidation of plasma proteins is not increased after supplementation with eicosapentaenoic and docosahexaenoic acids. Am. J. Clin. Nutr., 2000, 72, 731-737.

Wassal, S.R., Stillwell, W., 2009. Polyunsaturated fatty-acid-cholesterol interactions : Domain formation in membranes. Biochim. Biophys. Acta, 1788, 24-32.

Williams, J.A., Batten, S.E., Harris, M., Rockett, B.D., Shaikh, S.R., Stillwell, W., Wassall, S.R., 2012. Docosaheaxaenoic and eicosapentaenoic acids segregate differently between raft and nonraft domains. Biophys. J., 103, 228-237.

Wong, S.W., Kwon, M.-J., Choi, A.M., Kim, H.-P., Nakahira, K., Hwang, D.H., 2009. Fatty acids modulate toll-like receptor 4 activation through regulation of receptor dimerization and recruitment into lipid rafts in a reactive oxygen species-dependent manner. J. Biol. Chem. 284, 27384-27392.

Wu, D., Cederbaum, A.I. 2009. Oxidative stress and alcoholic liver disease. Semin. Liver Dis., 29, 141-154.

Yacoub, L.K., Fogt, F., Griniuviene, B., Nanji, AA., 1995. Apoptosis and bcl-2 protein expression in experimental alcoholic liver disease in the rat. Alcohol. Clin. Exp. Res. 19, 854859.

Yaqoob, P., Shaikh, S.R., 2010. The nutritional and clinical significance of lipid rafts. Curr. Opin. Clin. Nutr. Metab. Care. 13, 156-166.

Ye, S., Tan, L., Ma, J., Shi, Q., Li, J., 2010. Polyunsaturated docosahexaenoic acid suppresses oxidative stress induced endothelial cell calcium influx by altering lipid composition in membrane caveolar rafts. Prostaglandins Leukot. Essent. Fatty Acids. 83, 37- 
43.

Zhu, H., Jia, Z., Misra, H., Li, Y.R. 2012. Oxidative stress and redox signaling mechanisms of alcoholic liver disease : updated experimental and clinical evidence. J. Dig. Dis. 13, 133142. 


\section{Legends to figures}

(A)

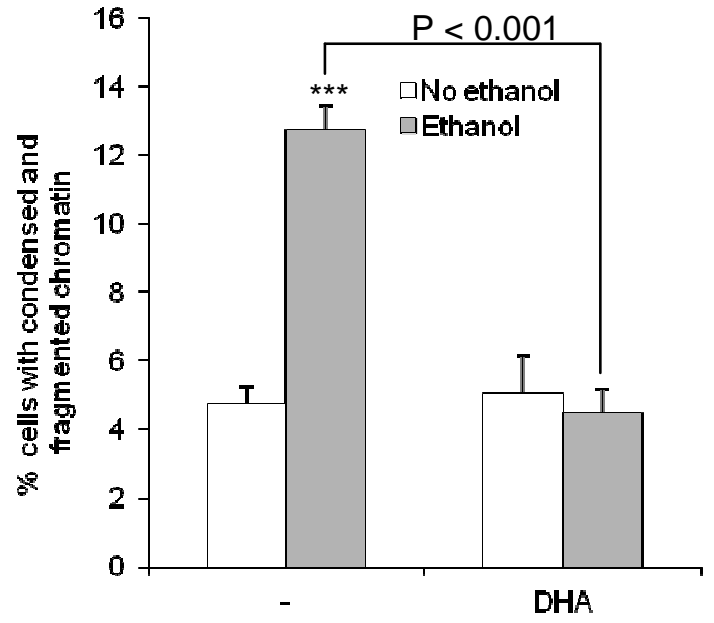

(C)

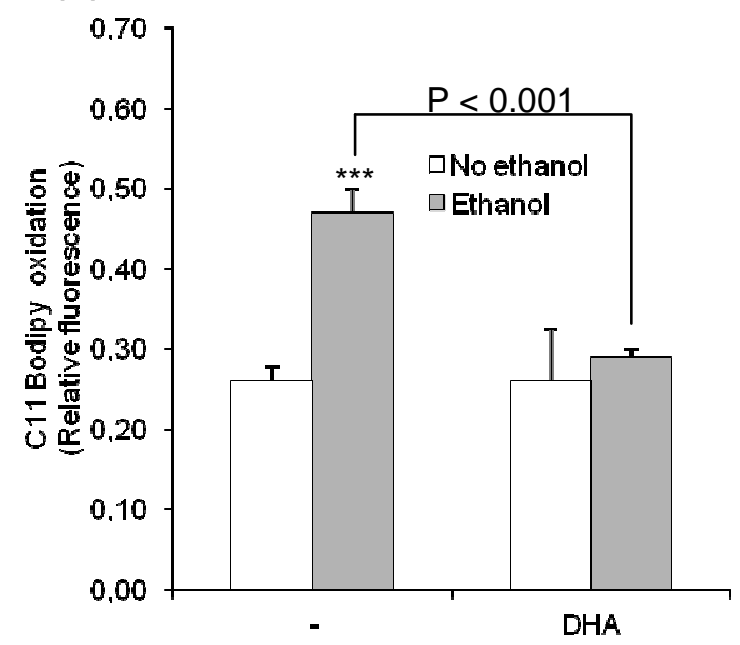

(B)

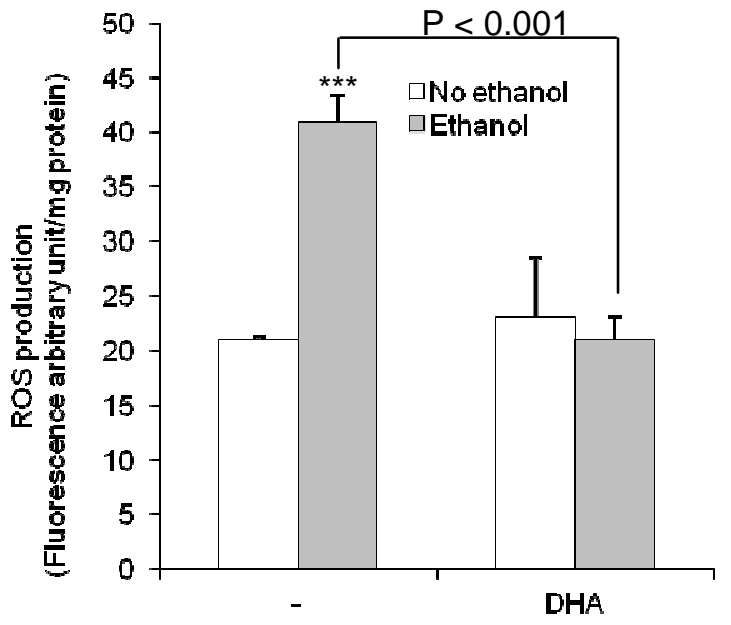

(D)

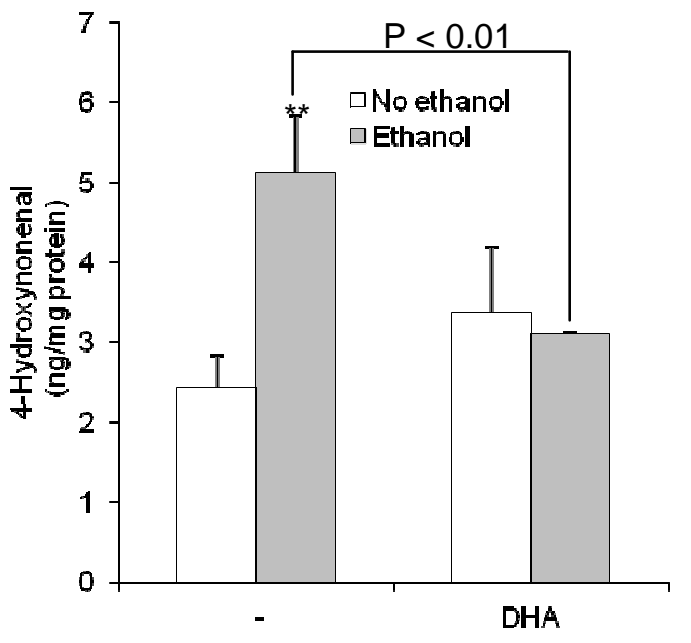

Figure 1. DHA induced protective effect towards ethanol-induced toxicity in primary rat hepatocytes evaluated by (A) cell death and (B-D) oxidative stress. Oxidative stress was assessed by (B) ROS production and (C-D) lipid peroxidation ((C) oxidation of C11BODIPY $^{581 / 591}$, a polyunsaturated fatty acid like, and (D) dosage of free 4-hydroxynonenal, an oxidized fatty acid by-product). Rat hepatocytes were pretreated for 18 hours with $200 \mu \mathrm{M}$ DHA before $50 \mathrm{mM}$ ethanol addition or not for a further 1- or 5-hours incubation. Some cultures were not pre-incubated with DHA. Cell death was determined by staining nuclear chromatin condensation with Hoechst 33342 (5-hours treatment with ethanol). ROS 
production was analyzed by the fluorescence of DHE (1-hour treatment with ethanol). The oxidation of C11-BODIPY ${ }^{581 / 591}$ was measured by the relative fluorescence of oxidized probe/total probe (5-hours treatment with ethanol). 4-hydroxynonenal was measured by GCMS (5-hours treatment with ethanol). Values are the mean \pm SD of three independent experiments. Ethanol-treated cultures versus cultures without ethanol: $* * \mathrm{P}<0.01$, *** $\mathrm{P}<$ 0.001 .

(A)

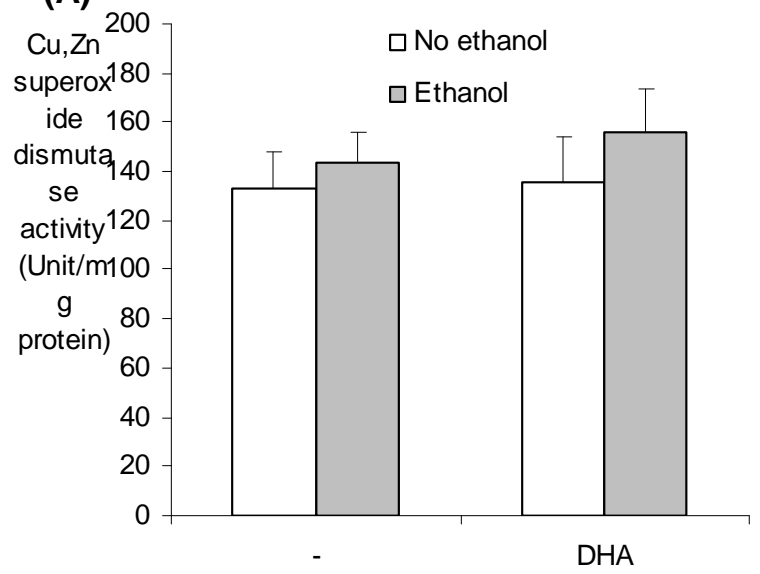

(C)

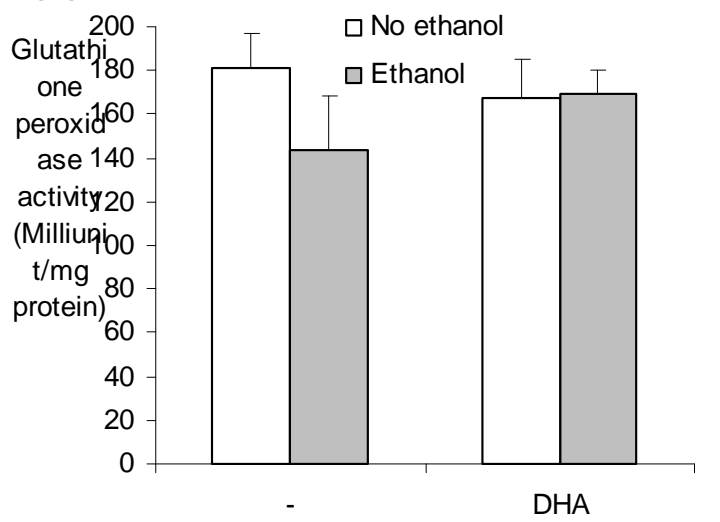

(B)

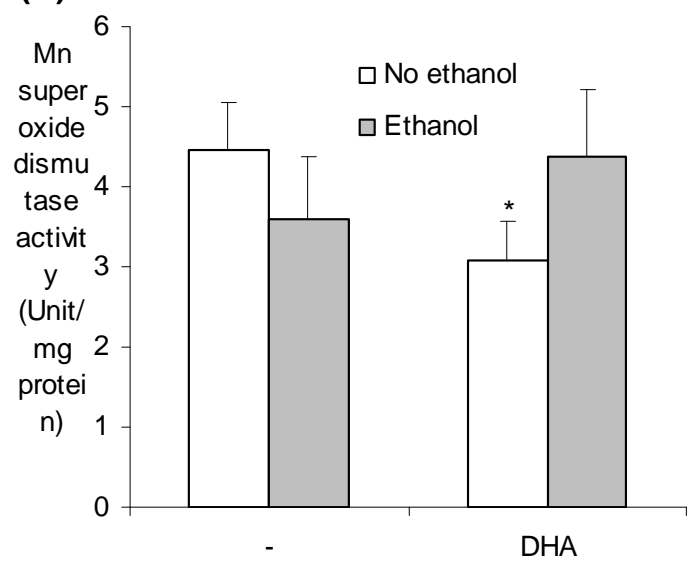

(D)

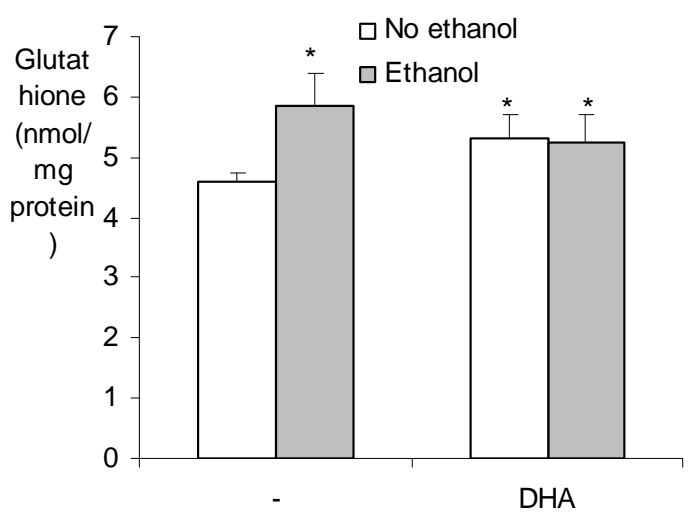

Figure 2. DHA did not increase the antioxidant status of ethanol-treated hepatocytes : (A) $\mathrm{Cu}, \mathrm{Zn}$ superoxide dismutase, (B) $\mathrm{Mn}$ superoxide dismutase, (C) gluthatione peroxidase activities, and (D) glutathione concentration. Rat hepatocytes were pretreated for 18 hours with $200 \mu \mathrm{M}$ DHA before $50 \mathrm{mM}$ ethanol addition or not for a further 5-hours incubation. Some cultures were not pre-incubated with DHA. Intracellular antioxidants were tested by colorimetric assays. Values are the mean \pm SD of three independent experiments. Ethanoltreated cultures versus cultures without ethanol: $* \mathrm{P}<0.05$. 
(A)

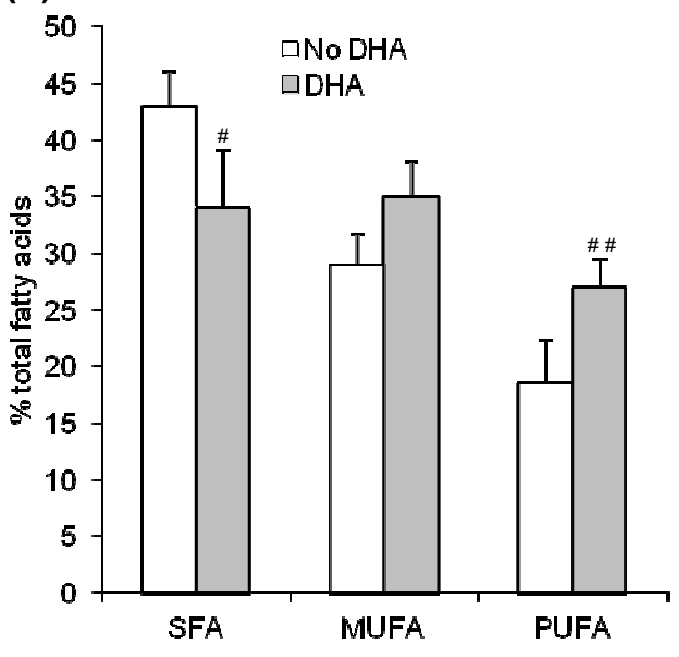

(B)

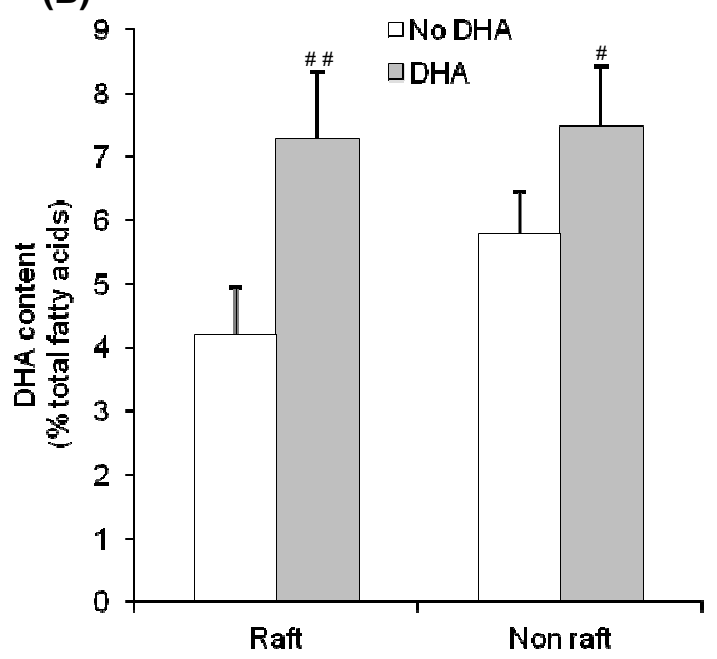

(C)

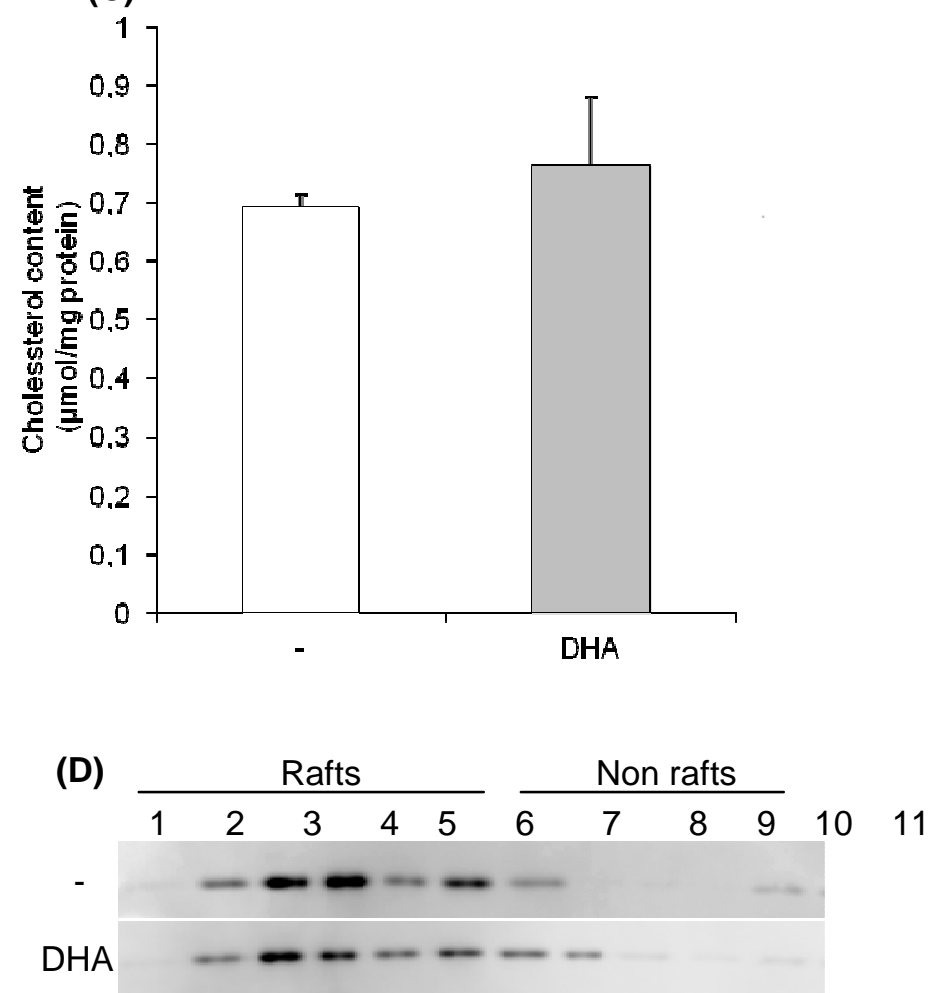

Figure 3. DHA modified composition of lipid rafts evaluated by (A) total fatty acid profile (SFA: saturated fatty acids, MUFA: monounsaturated fatty acids, PUFA: polyunsaturated fatty acids), (B) DHA content, (C) cholesterol amount, (D) flotillin expression. Rat hepatocytes were pretreated for 18 hours with $200 \mu \mathrm{M}$ DHA. Lipid rafts were obtained after lysis of hepatocytes in ice-cold 1\% Triton X-100 and fractionation on a sucrose density gradient by ultracentrifugation. Lipids from each detergent-resistant raft fractions (1-6) were extracted before separation by gas chromatography equipped with a flame ionization detector. An equal protein amount of each fraction was submitted to western blotting for analysis of 
flotillin-1 expression. One representative of three independent experiments is shown. Values are the mean $\pm \mathrm{SD}$ of three independent experiments. DHA-treated versus untreated cultures : ${ }^{\#} \mathrm{P}<0.05$ and ${ }^{\#} \mathrm{P}<0.01$.
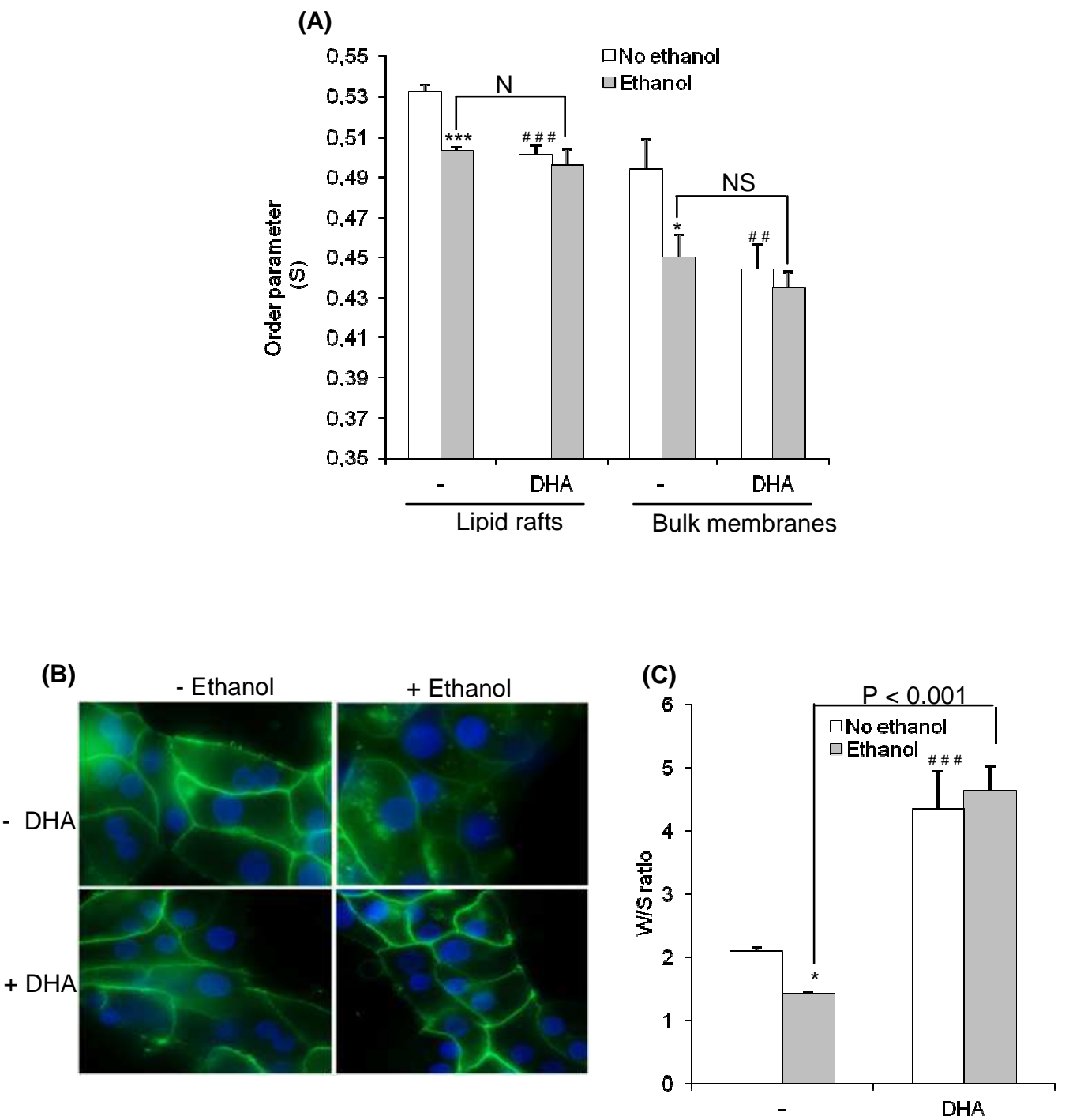

Figure 4. Structural perturbation of lipid rafts by DHA protected from ethanol-induced lipid raft clustering : (A) lipid raft membrane fluidity, (B) lipid raft aggregation, (C) lipid raft protein interactions. Rat hepatocytes were pretreated for 18 hours with $200 \mu \mathrm{M}$ DHA before $50 \mathrm{mM}$ ethanol addition or not for a further 1-hour incubation. Lipid rafts were obtained after lysis of hepatocytes in ice-cold 1\% Triton X-100 and fractionation on a sucrose density gradient by ultracentrifugation. (A) Membrane fluidity was monitored by electron paramagnetic resonance analysis of 12-doxyl stearic acid embedded in membranes. This analysis resulted in the determination of the order parameter $\mathrm{S}$ which is inversely related to membrane fluidity. (B) Lipid raft aggregation was visualized by fluorescence microscopy 
with cholera toxin subunit B conjugated with Alexa Fluor 488 which binds the raft-associated glycosphingolipid GM1. One representative of three independent experiments is shown. (C) Protein structural changes were examined with tetramethyl-4-maleimidopiperidine- 1-oxyl (MAL-6), a thiol-specific protein spin label. Values are the mean \pm SD of three independent experiments. Ethanol-treated versus cultures without ethanol: $* P<0.05$, $* * \mathrm{P}<0.01$, $* * * \mathrm{P}<$ 0.001. DHA-treated versus untreated cultures: ${ }^{\#} \mathrm{P}<0.05,{ }^{\#} \mathrm{P}<0.01$ and ${ }^{\#}{ }^{\#} \mathrm{P}<0.001$. NS : not significant. 

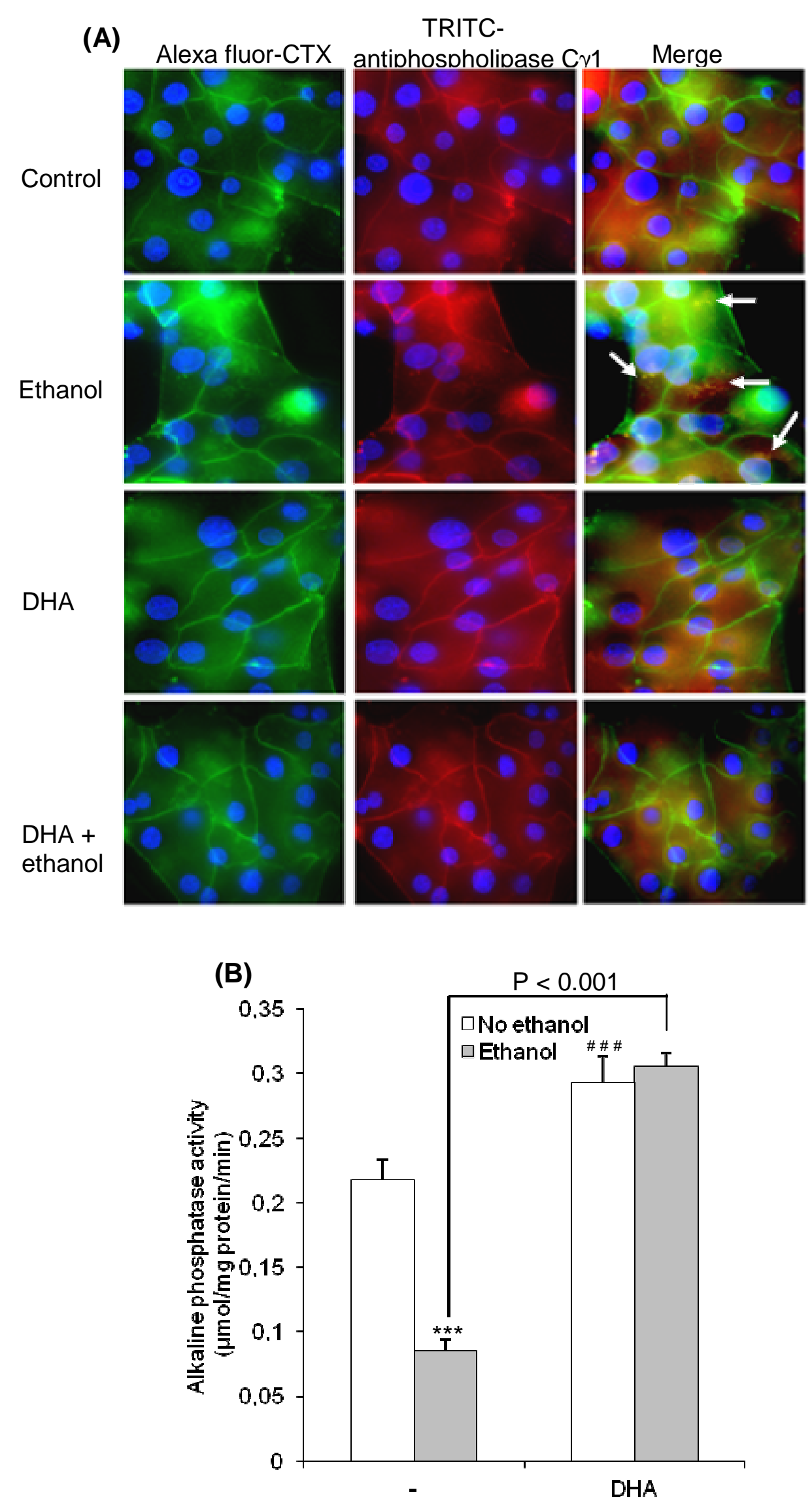
Figure 5. DHA inhibited ethanol-induced phospholipase $C \gamma 1$ translocation into lipid rafts (A) and subsequent activation (B). Rat hepatocytes were pretreated for 18 hours with $200 \mu \mathrm{M}$ DHA, before $50 \mathrm{mM}$ ethanol addition or not for a further 1-hour incubation. (A) Rat hepatocytes were co-stained by Alexa Fluor cholera toxin subunit B (CTX; green fluorescence at left) and tetramethyl rhodamine isothiocyanate (TRITC)- conjugated antigen to phospholipase $\mathrm{C} \gamma 1$ (anti-PLC $\gamma 1$; red fluorescence in middle). The merge of both images shows yellow areas (at right) that represent colocalization of monosialotetrahexosylganglioside and PLC $\gamma 1$. One representative of three independent experiments is shown. (B) Lipid rafts were obtained after lysis of hepatocytes in ice-cold $1 \%$ Triton X-100 and fractionation on a sucrose density gradient by ultracentrifugation, and then analyzed for alkaline phosphatase activity which is inversely related to PLC $\gamma 1$ activity. Values are the mean \pm SD of three independent experiments. Ethanol-treated versus cultures without ethanol: ***P $\mathrm{P} 0.001$. DHA-treated versus untreated cultures: ${ }^{\# \#} \mathrm{P}<0.001$. 

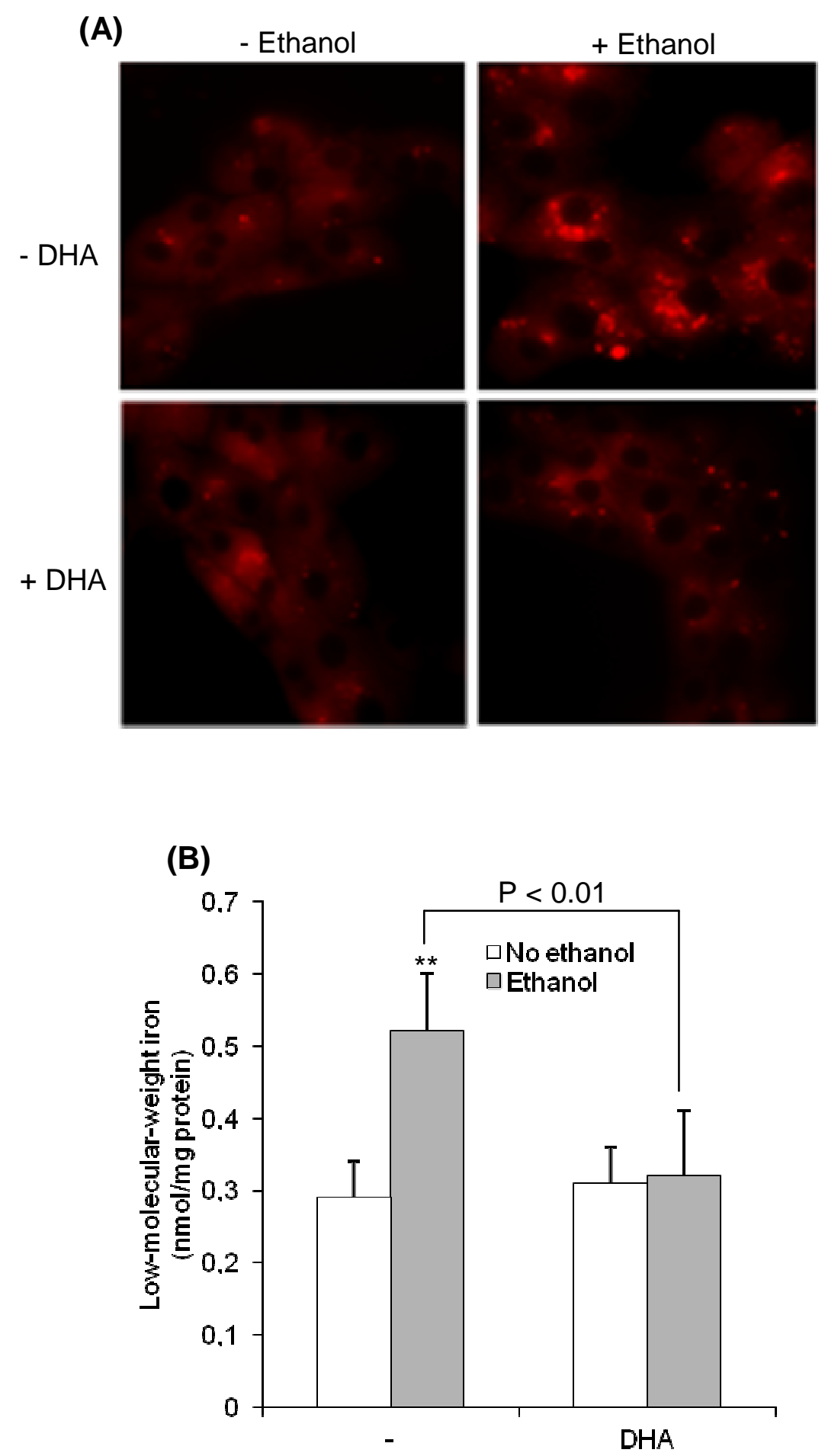

Figure 6. DHA prevented ethanol-induced lysosome accumulation (A) and subsequent elevation of cellular LMW iron content (B). Rat hepatocytes were pretreated for 18 hours with $200 \mu \mathrm{M}$ DHA, before $50 \mathrm{mM}$ ethanol addition or not for a further 1- or 1.5- hour incubation. (A) Lysosomes were visualized by fluorescence microscopy using $200 \mathrm{nM}$ LysoTracker, a lysosomal marker. Lysosomes were characterized by bright red fluorescence (1-hour treatment with ethanol). One representative of three independent experiments is 
shown (B) Low-molecular-weight iron was determined by EPR analysis after chelation by 3 $\mathrm{mM}$ deferiprone (1.5-hour treatment with ethanol). Values are the mean $\pm \mathrm{SD}$ of three independent experiments. Ethanol-treated versus cultures without ethanol: **P $<0.01$.

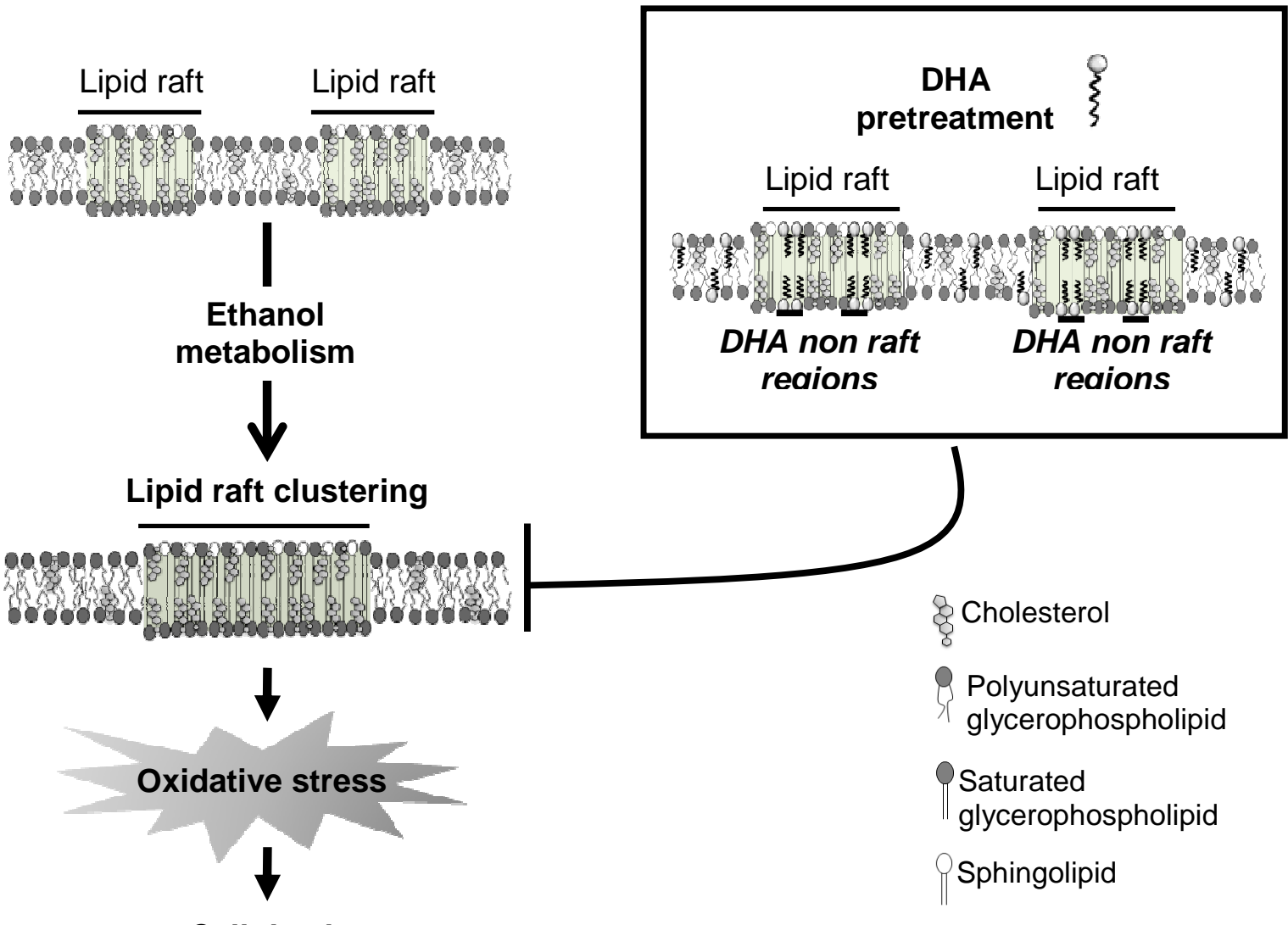

Figure 7. Proposed mechanism for the role of lipid rafts in the protection provided by DHA against ethanol-induced oxidative stress and cell death in rat hepatocytes. DHA, by its incorporation into lipid rafts, might generate non raft regions inside lipid rafts preventing from ethanol-induced lipid raft clustering and hence PLC $\gamma 1$ translocation into rafts. Consequently, DHA would inhibit ethanol-induced oxidative stress and cell death. 